\title{
Microbial ecology of the newly discovered serpentinite-hosted Old City hydrothermal field (southwest Indian ridge)
}

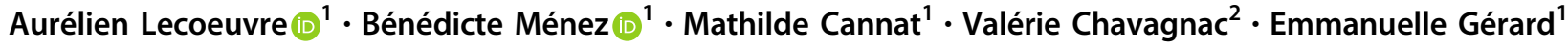

Received: 3 March 2020 / Revised: 13 October 2020 / Accepted: 19 October 2020 / Published online: 2 November 2020

(c) The Author(s) 2020. This article is published with open access

\begin{abstract}
Lost City (mid-Atlantic ridge) is a unique oceanic hydrothermal field where carbonate-brucite chimneys are colonized by a single phylotype of archaeal Methanosarcinales, as well as sulfur- and methane-metabolizing bacteria. So far, only one submarine analog of Lost City has been characterized, the Prony Bay hydrothermal field (New Caledonia), which nonetheless shows more microbiological similarities with ecosystems associated with continental ophiolites. This study presents the microbial ecology of the 'Lost City'-type Old City hydrothermal field, recently discovered along the southwest Indian ridge. Five carbonate-brucite chimneys were sampled and subjected to mineralogical and geochemical analyses, microimaging, as well as $16 \mathrm{~S}$ rRNA-encoding gene and metagenomic sequencing. Dominant taxa and metabolisms vary between chimneys, in conjunction with the predicted redox state, while potential formate- and CO-metabolizing microorganisms as well as sulfur-metabolizing bacteria are always abundant. We hypothesize that the variable environmental conditions resulting from the slow and diffuse hydrothermal fluid discharge that currently characterizes Old City could lead to different microbial populations between chimneys that utilize $\mathrm{CO}$ and formate differently as carbon or electron sources. Old City discovery and this first description of its microbial ecology opens up attractive perspectives for understanding environmental factors shaping communities and metabolisms in oceanic serpentinite-hosted ecosystems.
\end{abstract}

\section{Introduction}

Serpentinization is the hydration of mantle-derived rocks that produces fluids enriched in molecular hydrogen $\left(\mathrm{H}_{2}\right)$. These reducing fluids can react with inorganic carbon to form methane, formate, and other low molecular-weight hydrocarbons, and organic acids [1]. They discharge through submarine hydrothermal vents or springs located in ophiolites where they provide energy and carbon sources for microbial life, while mixing with oxidized seawater or meteoric fluids $[2,3]$.

Supplementary information The online version of this article (https:// doi.org/10.1038/s41396-020-00816-7) contains supplementary material, which is available to authorized users.

Aurélien Lecoeuvre

lecoeuvre@ipgp.fr

1 Université de Paris, Institut de physique du globe de Paris, CNRS UMR 7154, Paris, France

2 Université de Toulouse, Géosciences Environnement Toulouse, CNRS UMR 5563, Toulouse, France
Oceanic serpentinite-hosted hydrothermal fields are found at (ultra)slow spreading ridges where mantle rocks are exhumed by tectonic processes and infiltrated by seawater $[4,5]$. The emblematic Lost City hydrothermal field (LCHF, $30^{\circ} \mathrm{N}$, mid-Atlantic ridge) is characterized by moderate temperature (up to $90-116^{\circ} \mathrm{C}$ ), metal- and $\mathrm{CO}_{2}$ depleted, high $\mathrm{pH}$ (9-11) fluids that actively discharge through carbonate-brucite chimneys [6, 7]. 'Lost City'-type alkaline hydrothermal fields have also been discovered in the Mariana forearc [8] and at Prony Bay, New Caledonia [9]. These sites relate respectively to a subduction zone and an ophiolite. Fluid recharge at the Prony Bay hydrothermal field (PBHF) is mainly influenced by meteoric water, while the Shinkai Seep site of Mariana forearc and LCHF are fed by seawater.

Microbial communities sustained by serpentinization have recently been explored using next-generation sequencing and '-omic' technologies, although oceanic hydrothermal systems remain poorly explored compared to terrestrial springs due to difficulties in discovering and sampling sites at great water depth. Microbial taxa inhabiting LCHF chimneys differ from other serpentinite-hosted ecosystems [10-12], and even from PBHF [13-16]. Nevertheless, LCHF shares some 
microbiological commonalities with these other serpentinization-influenced habitats, including its extremely low taxonomic diversity [10, 12]. LCHF biofilms are dominated by methane-, $\mathrm{H}_{2}$ - and sulfur-metabolizing microorganisms with a unique archaeal phylotype of Methanosarcinales (the Lost City Methanosarcinales, LCMS) representing up to $81 \%$ of the community $[11,12,17]$. The LCMS metabolism can be versatile, and single species are capable of both hydrogenotrophic methanogenesis and anaerobic methanotrophy [18]. Sulfur-oxidizing Proteobacteria are represented by aerobic Rhodobacterales and Thiomicrospirales (formerly included in Thiotrichales). The LCHF microbial community is spatially heterogeneous, the LCMS being located inside the anoxic chimneys, while Thiomicrospirales colonize oxic/ anoxic interfaces [12]. Methane-oxidizing bacteria requiring seawater $\mathrm{O}_{2}$ have been proposed as colonizers of the external parts of less active chimneys [12].

Despite differences in the composition of microbial communities retrieved at PBHF compared to LCHF, PBHF chimneys interestingly harbor Archaea related to LCMS and to another Methanosarcinales phylotype (The Cedars Methanosarcinales, TCMS) [15], identified in springs of The Cedars ophiolite (California, USA [19]). The dominant Bacteria in PBHF relate to anaerobic Firmicutes and aerobic or facultative anaerobic Chloroflexi, Proteobacteria, and Bipolaricaulota (formerly Acetothermia) [13-16]. The co-occurrence of aerobic and anaerobic metabolisms at both LCHF and PBHF has been attributed to variable influences of the hydrothermal discharge creating anoxic environments within chimneys and of oxidized seawater intrusions from outside the chimneys $[12,15]$. However, since PBHF represents the only submarine analog of LCHF identified to date, the factors driving microbial ecology in these systems remain unclear.

Here, we describe the microbial ecology of the Old City hydrothermal field (OCHF), an oceanic 'Lost City'-type hydrothermal site recently discovered along the southwest Indian ridge (SWIR) [20, 21]. Our study of the microbial diversity and its metabolic potential reveals significant taxonomic and metabolic heterogeneities between chimneys. By integrating mineralogical, geochemical, microimaging, microbial diversity, and metagenomic approaches, we hypothesize that the slow and diffuse hydrothermal discharge at Old City shapes the differences in microbial community composition and potential metabolisms between chimneys.

\section{Materials and methods}

\section{Study site and sample processing}

OCHF was discovered at $27^{\circ} 50^{\prime} 6^{\prime \prime} \mathrm{S}$ to $64^{\circ} 35^{\prime} 6^{\prime \prime} \mathrm{E}$ during the ROVSMOOTH cruise (December 2016 to January

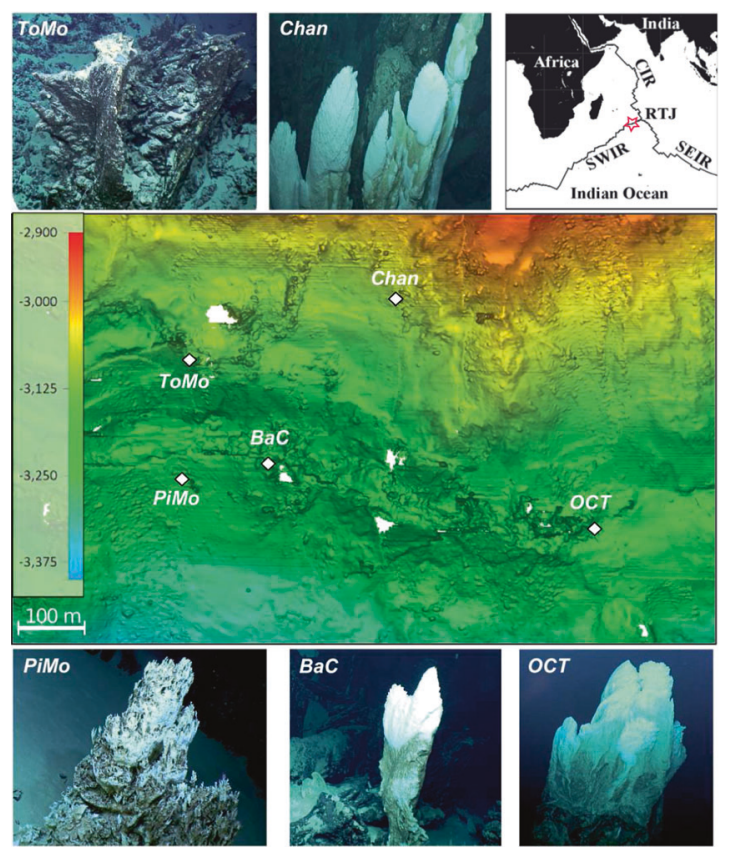

Fig. 1 Microbathymetric map (in meters below sea level) of the Old City hydrothermal field $\left(27^{\circ} 50^{\prime} 6^{\prime \prime} \mathrm{S}\right.$ to $64^{\circ} 35^{\prime} 6^{\prime \prime} \mathrm{E}$; southwest Indian ridge) and locations of vents (with dive photographs) sampled for this study using the remotely operated vehicle Victor 6000. Samples were collected from the recently formed white mineral deposit of potentially active chimneys $(B a C$, Chan, and $O C T)$ or from apparently less active chimneys with dark coating made of biological mats and manganese deposits (Tomo and Pimo). Details on samples can be found in Supplementary Table S1 and Supplementary methods. Videos of chimney sampling are also available at https://campagnes. flotteoceanographique.fr/campagnes/16002000/fr/. The red star in the context map reproduced from [22] indicates the region of the SWIR investigated during the ROVSMOOTH cruise. CIR central Indian ridge, RTJ Rodrigues triple junction, SEIR southeast Indian ridge.

2017, R/V Pourquoi pas?, P.I. M. Cannat, IPGP [20, 21]). It is a serpentinite-hosted hydrothermal site located in a magma-poor area (less than $3 \%$ gabbros) of the eastern SWIR (Fig. 1) [5, 22]. This site is therefore particularly relevant to study the influence of serpentinization of mantlederived rocks alone on microbial communities. OCHF sits at $\sim 3,100 \mathrm{~m}$ below sea level (Supplementary Table S1) and consists of whitish vents (Fig. 1).

Five distinct chimney samples were collected (Fig. 1 and Supplementary methods). Three (i.e., BaC, Chan, and $O C T$ ) show recently formed deposits recognizable by their white color and highly porous and friable structure $[10,16]$. In contrast, PiMo and ToMo have dark coating made of biological mats and manganese deposits. Videos of chimney sampling can be found at https://campagnes.flotteoceanogra phique.fr/campagnes/16002000/fr/ (Sampling videos for BaC, Chan, OCT, PiMo and ToMo are identified as 22773, 23014, 22788, 22772 and 23030, respectively).

Chimney samples were characterized for their mineralogical and elemental composition using X-ray diffraction 
(XRD) and inductively coupled plasma-mass spectrometry (ICP-MS), respectively. Microimaging was performed using confocal laser scanning microscopy (CLSM) and scanning electron microscopy (SEM). DNA was extracted from chimney samples following the phenol-chloroform protocol previously used for PBHF carbonate chimneys [14]. High-quality DNA extracts (up to $150 \mathrm{ng}$ ) were used for tag sequencing of the hypervariable region V4-V5 of the 16S rRNA-encoding genes and for shotgun metagenomics. All raw reads were submitted to the National Center for Biotechnology Information (NCBI) Sequence Read Archive under Bioproject accession number PRJNA556392. For all chimneys sampled (except ToMo), fluids were also sampled as close as possible to putative chimney fluid outlets and in ambient seawater (Supplementary methods). Fluids were analyzed using inductively coupled plasma-optical emission spectrometry (ICP-OES). All analytical protocols and conditions are detailed in Supplementary methods, including results of control experiments (e.g., Supplementary Fig. S1).

\section{Amplicon filtering and microbial diversity analysis}

High-quality sequences from tag sequencing were clustered into amplicon sequence variants (ASVs) by applying the minimum entropy decomposition algorithm [23] with default parameters but the minimum abundance set to 25 to remove noising features, while conserving relative diversities in each sample. Chimeras were identified in the representative ASV sequences with the FindChimeras algorithm implemented in the DECIPHER package for $\mathrm{R}$ [24, 25] and were then removed. Representative node sequences were submitted to the SILVAngs pipeline (https://www.arb-silva.de/ngs/) for taxonomic assignment of ASVs against the SILVA database release 132 [26]. As no DNA was amplified from procedural controls, we removed commonly identified contaminants [27] based on ASV taxonomic classification at the genus level (Supplementary Table S2). Taxa relative abundance in each sample was visualized using the ggplot2 package [28].

Filtered ASVs were imported in R version 3.6.0 and normalized using scaling factors calculated by the metagenomeSeq package [29]. Similarities and dissimilarities between communities were respectively evaluated using Bray-Curtis index with the anosim function and PERMANOVA implemented in the adonis function of the Vegan package [30], with 999 repetitions each time. Potential correlations between chimney microbial communities and associated mineralogical and elemental compositions were evaluated with Mantel tests based on Pearson's productmoment or Spearman's rank correlations implemented in the Vegan package [30].

\section{Metagenome analysis}

Quality-filtered reads were assembled de novo with MEGAHIT v1.13 [31] with a minimum contig length of $1,000 \mathrm{bp}$ and default parameters. For each sample, reads were mapped to the assembled contigs with Bowtie2 [32]. Mapped reads were counted for each gene with the featureCounts function of the Rsubread package for R [33]. Gene abundances were then normalized using the TMM normalization method implemented in the R package edgeR [34].

To infer the taxonomy of all genes predicted from metagenomes, their sequence similarities were evaluated against the non-redundant NCBI database using Diamond blastp tool [35] with an $e$ value cutoff of $10^{-5}$. The most confident taxonomic rank assigned to each aligned gene sequence was predicted with the lowest common ancestor (LCA) algorithm implemented in MEGAN6 [36]. In addition to taxonomic annotation of all predicted genes, near full-length 16S rRNA-encoding genes were reconstructed for phylogenetic analysis (Supplementary methods). The relative abundance of bacterial and archaeal lineages in metagenomes was evaluated based on the relative abundance of (1) all retrieved genes, (2) 12 or 40 single-copy genes shared between all lineages as suggested by [37, 38], and (3) reconstructed near full-length 16S rRNA-encoding genes.

A set of marker genes (Supplementary Table S3) with normalized abundances was retrieved and imported in $\mathrm{R}$ for comparison and visualization using ggplot2 package [28]. Functional annotation of contigs was performed with the PROKKA pipeline [39] against the integrated custom database. In addition, protein sequences of genes identified by Prodigal [40] were submitted to GhostKOALA server (http://www.kegg.jp/ghostkoala/) to retrieve KEGG orthology [41] for each gene. Since some genes coding for hydrogenases are absent from the KEGG database, we also searched for hydrogenases domains [42, 43] in our metagenomes (Supplementary methods). All protein sequences of specific microbial lineages were finally retrieved and submitted to the GhostKOALA server in order to assess the completion of encoded metabolic pathways and to provide a more complete picture of the potential physiology of these lineages.

\section{Average carbon oxidation state of proteins predicted from metagenomes}

The average carbon oxidation state $\left(Z_{C}\right)$ of protein sequences predicted from PROKKA [39] was calculated as described in [44]. Protein sequences were imported into $R$ version 3.6.0 using the read.fasta function of the CHNOSZ package [45]. Since we used complete protein sequences derived from co-assembled contigs rather than reads, the amino acid counts of each protein were normalized by the 


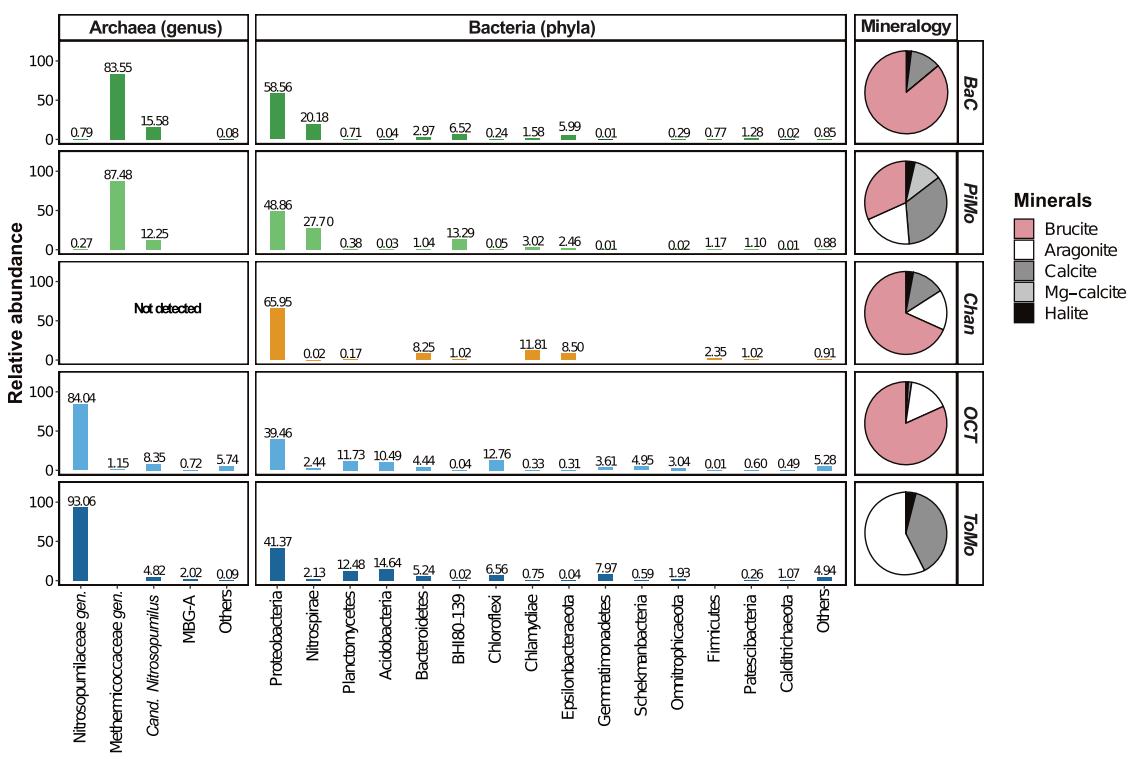

Fig. 2 Relative abundance of taxa obtained from representative ASV sequences retrieved from Old City chimneys (at the genus and phylum level for Archaea and Bacteria, respectively and using the SILVA database release 132 [26]). Semi-quantitative X-ray diffraction results presenting the mineralogy of sampled chimneys are also shown as pie charts. The predominance of brucite is observed in most samples while ToMo is dominated by calcium carbonates (calcite and aragonite) and PiMo shows a similarly high relative content in

abundance of the corresponding encoding genes obtained with Bowtie2 [32]. This normalization yields abundanceweighted values for each protein and allows comparison between samples. To account for intra-sample variations, sequences were randomly subsampled 100 times to generate a set of 200,000 amino acids on average for each sample, and were normalized by their length. $Z_{C}$ values were finally computed using the $Z C$ (protein.formula(input)) function of $\mathrm{R}$ package CHNOSZ [45]. Results from subsampled sequences were used to calculate mean $Z_{C}$ value and associated standard deviation for each sample, all plotted using ggplot2 package [28]. To assess differences between samples in $Z_{\mathrm{C}}$ mean values and variances, we respectively performed Welch's $t$-test and pairwise Wilcoxon rank sum test in $\mathrm{R}$ version 3.6.0. Note that the overall approach only highlights the $Z_{C}$ profile of encoded protein sequences and ignores potential differences between gene, mRNA and protein abundances [e.g., 46, 47].

\section{Results}

\section{Fluid compositions}

The compositions of fluids collected as close as possible to putative chimney fluid outlets and that of ambient seawater differ slightly from standard seawater (Supplementary calcite. Cand. Nitrosopumilus Candidatus Nitrosopumilus, MBG-A Marine Benthic Group-A, BHI80-139 candidate phylum BHI80-139/ NPL-UPA2. Nitrosopumilaceae and Methermicoccaceae are two archaeal families with unclassified genera (gen.). "Others" includes all taxa that do not show a relative abundance higher than $1 \%$ in at least one chimney sample. It includes Actinobacteria and Bipolaricaulota (formerly Acetothermia) phyla.

Table S4). They show higher $\mathrm{pH}$ values and $\mathrm{Mg}, \mathrm{Ca}, \mathrm{Na}$, and $\mathrm{Li}$ concentrations. The $\mathrm{pH}$ values of fluids collected from chimneys range from $7.88(O C T)$ to 8.18 (PiMo). This $\mathrm{pH}$ value is slightly higher than that of ambient seawater (average $\mathrm{pH}$ 7.83), but their elemental compositions are similar.

\section{Hydrothermal chimneys' elemental and mineralogical compositions}

OCHF chimney samples show variable chemical and mineralogical compositions. All have low metal concentrations (Supplementary Table S5), while the predominance of $\mathrm{Mg}$ and $\mathrm{Ca}$ depends on the chimney sampled. $P i M o$ is the most enriched in $\mathrm{Si}$ and metals (i.e., $\mathrm{Fe}, \mathrm{Mn}, \mathrm{Zn}$, and Ni). Semi-quantitative XRD results (Fig. 2) show that samples are mainly made of brucite and minor calcium carbonates, with the exception of ToMo, which is composed only of calcium carbonates (i.e., calcite and aragonite) and, to a lesser extent, PiMo, which shows a high relative content in calcite. ToMo sample is also enriched in $\mathrm{Sr}$, in agreement with its high relative content in aragonite.

\section{Microscopic evidence for chimney microbial colonization}

CLSM shows that chimneys are colonized by microorganisms grouped in clusters of cells attached to minerals 


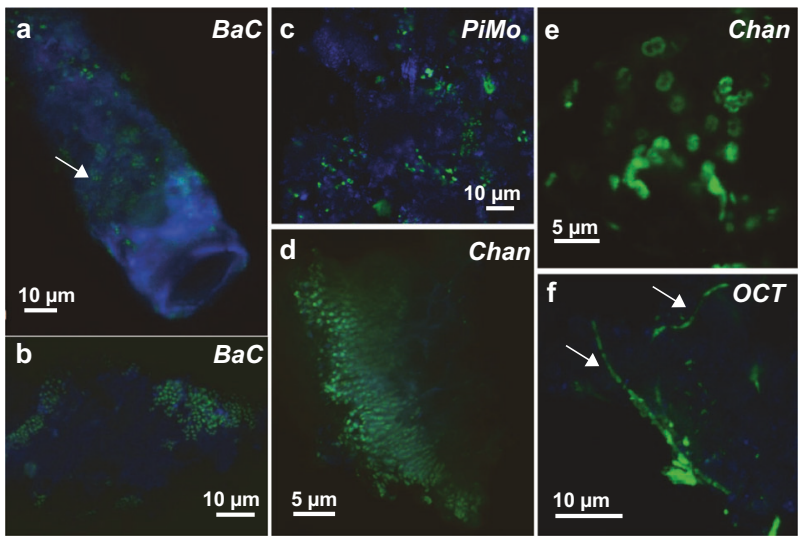

Fig. 3 Confocal laser scanning microscopy images showing different microbial morphotypes in chimney samples. Rod-shaped cells (white arrows in $\mathbf{a}, \mathbf{f}$ ) and coccoidal cells (a-d) sometimes organized in filaments $(\mathbf{d}, \mathbf{f})$ are dominant in vent conduits where they attach to minerals here autofluorescing in blue $(\mathbf{a}-\mathbf{c})$. Diplococci, characteristic of methylotrophs, can be observed in Chan sample (e).

(Fig. 3). Cell sizes range from 0.2 to $5 \mu \mathrm{m}$, with the smallest rod-shaped cells found in $\mathrm{BaC}$ and PiMo $(0.5 \times$ $0.2 \mu \mathrm{m}$; Fig. 3a-c), while the longest are found in $O C T$ $(5 \times 1 \mu \mathrm{m}$; Fig. $3 \mathrm{f})$. Dense biofilms consisting of small coccoidal cells $(0.5 \mu \mathrm{m})$, sometimes organized in diplococci or tetrads, are present in $\mathrm{BaC}$ and PiMo (Fig. 3b, c). Chan is particularly enriched in diplococci $(1-3 \mu \mathrm{m}$ long; Fig. 3e) often organized in chains (Fig. 3d). Filamentous shapes are particularly abundant in $O C T$ (30-35 $\mu \mathrm{m}$ long; Fig. 3f), but have also been observed in $B a C$ (10-110 $\mu \mathrm{m}$ long).

Evidence of microbial colonization is less clear with SEM, possibly due to the widespread encrustation of cells in minerals (Supplementary Fig. S2). However, networks of thin carbonaceous filaments are ubiquitous (Supplementary Fig. S2a, e). By analogy to what has been observed in PBHF chimneys [16], they likely represent extracellular polymeric substances. Some OCHF chimneys also show the presence of bacteriomorphs (Supplementary Fig. S2b) or long carbon-rich filamentous structures (several tens of micrometers long) coated with nano- to microcrystalline brucite (Supplementary Fig. S2d), which could lead to the large mineralized filaments frequently observed (Supplementary Fig. S2c), as also reported in PBHF chimneys [16].

\section{DNA quantification and sequence filtering}

DNA extractions led to concentration ranging from 0.06 to $4.20 \mu \mathrm{g} / \mathrm{g}$ of DNA per chimney samples. OCT and ToMo harbor relatively low DNA concentrations $(0.06$ and 0.21 $\mu \mathrm{g} / \mathrm{g}$, respectively) compared to other chimney samples. However, all produced high-quality amplicon sequences with an average of 148,217 and 82,906 quality filtered merged paired-end reads for Bacteria and Archaea, respectively (Supplementary Table S6). In addition, a total of 190,288,385 high-quality metagenomic paired-end reads were sequenced (Supplementary Table S6) and coassembled to 391,941 contigs with an average length of 2,000 nucleotides.

\section{Microbial community composition from tag sequencing}

Statistical analyses of similarities and dissimilarities show that the microbial communities of $\mathrm{BaC}$ and PiMo on the one hand and $O C T$ and ToMo on the other hand are significantly similar while Chan presents a distinct community (PERMANOVA tests, $r^{2}=0.67$ and $p<0.001$, respectively). However, Mantel tests suggest that microbial communities' diversity is not correlated with bulk chimney mineralogy and chemistry (Supplementary Table S7).

The relative abundance of taxonomic groups identified from 16S rRNA-encoding gene amplicons (i.e., from ASV sequences) confirms heterogeneities between samples for both Bacteria and Archaea (Fig. 2). while Proteobacteria dominate all samples, the other dominant phyla differ strongly between chimney samples. Uncultured Thermodesulfovibrionia (Nitrospirae) and candidate phylum BHI80-139 (also known as NPL-UPA2) are abundant in $\mathrm{BaC}$ and PiMo. In contrast, Bacteroidetes, Chlamydiae, and Epsilonbacteraeota are relatively abundant in Chan, while Planctomycetes, Acidobacteria and Chloroflexi are only well represented in $O C T$ and ToMo. The relative abundances of proteobacterial lineages also depend on samples (Supplementary Fig. S3). For Gammaproteobacteria, the Thiomicrospirales order prevails in $\mathrm{BaC}$ and $\mathrm{PiMo}$, while the Steroidobacterales order is more abundant in $O C T$ and ToMo. In contrast, Methylococcales-related sequences are 30 times more abundant in Chan compared to other chimney samples and at least three times more abundant than any other taxa in this sample. Alphaproteobacteria in $B a C$, $P i M o$, and Chan mostly group in the versatile Rhodobacterales order, while most of the alphaproteobacterial ASVs in $O C T$ and ToMo belong to the Rhodovibrionales and Kordiimonadales orders (Supplementary Fig. S3). In $\mathrm{BaC}, \mathrm{PiMo}$, and Chan, deltaproteobacterial ASVs are mainly represented by the sulfate reducing Desulfobacterales order, while Deltaproteobacteria are less abundant in $O C T$ and ToMo.

Archaea are not detected in Chan using tag sequencing. As observed for Bacteria, $\mathrm{BaC}$, and PiMo Archaea are highly similar with the dominance of ASVs related to the Methermicoccaceae family from the Methanosarcinales order (Fig. 2). In contrast, the most abundant taxon in $O C T$ and ToMo corresponds to unclassified Nitrosopumilaceae. 
Only Candidatus Nitrosopumilus is shared between samples at comparable abundance.

\section{Relative proportion of Archaea and Bacteria in metagenomes}

Lineage relative abundance profiles have also been established from metagenomes following four different approaches (Supplementary Fig. S4). They all show that Archaea are less abundant in $\mathrm{BaC}$ and PiMo with Euryarchaeota, and in particular Methanosarcinales, representing only $2-4 \%$ of all genes considered. In contrast, Thaumarchaeota, including the Nitrosopumilaceae family, are highly abundant in $O C T$ and ToMo, representing $17-40 \%$ and $11-28 \%$ of all genes, respectively. The mostly unclassified Euryarchaeota observed in Chan and ToMo are very low in abundance $(<1 \%$ of all genes).

\section{Phylogenetic analysis}

Based on the metagenomic datasets, we have reconstructed 364 high-quality near full-length 16S rRNA-encoding gene sequences. As shown in Fig. 4 and Supplementary Figs. S5-S7, these sequences group with all the dominant taxonomic groups highlighted by tag-sequencing community analysis (Fig. 2) despite differences in abundance (e.g., Actinobacteria and Acetothermia which are much more abundant in metagenomes; Supplementary Fig. S4).

$B a C$ and $P i M o$ share many similarities regarding their Bacteria and Archaea phylogenetic affiliations. Many Bacteria of these chimney samples closely group with clones retrieved from LCHF (Fig. 4 and Supplementary Figs. S5 and S6) including Thermodesulfovibrionia (Nitrospirae), dominant Thiomicrorhabdus (Gammaproteobacteria), and some Sulfurovum (Epsilonbacteraeota) and Desulfobulbus (Deltaproteobacteria). Sequences grouping with Chloroflexi Dehalococcoidia (MSBL5) relate to environmental clones from PBHF and The Cedars. Interestingly, three reconstructed near full-length $16 \mathrm{~S}$ rRNA-encoding genes group with candidate phylum BHI80-139/NPL-UPA2 in a cluster formed by clones from LCHF, PBHF, The Cedars and Baby Bare seamount on the Juan de Fuca ridge flank (Fig. 4). Two near fulllength $16 \mathrm{~S}$ rRNA-encoding gene sequences from $\mathrm{BaC}$ and PiMo closely relate to TCMS (Supplementary Fig. S7).

Numerous bacterial and archaeal near full-length $16 \mathrm{~S}$ rRNA-encoding genes from $O C T$ and ToMo closely group with environmental clones from deep marine sediments, polymetallic nodules, and sometimes from the ultramafic rock-hosted Logatchev hydrothermal field. In contrast, Chan includes bacterial phylotypes grouping with more diverse environments, including macrofauna bionts, in addition to marine sediments and hydrothermal vents (Fig. 4 and Supplementary Figs. S5-S7).

\section{Metabolic potential for C1 compounds}

Most of the key metabolic genes involved in $\mathrm{C} 1 \mathrm{com}$ pounds' metabolisms (Supplementary Table S3) are detected in all five metagenomes, but their abundance varies similarly to taxonomic diversity (Fig. 5a). However, the key gene coding for the methyl-coenzyme M reductase ( $\mathrm{mcrA}$ ) involved in methanogenesis is not detected in any metagenome, despite the presence of Methanosarcinales in $\mathrm{BaC}$ and PiMo. No complete or nearly complete methanogenesis pathways (including those involving $\mathrm{CO}_{2}$, acetate, methanol or methylamine) can be detected in the OCHF archaeal lineages. In addition, the genes involved in aerobic methanotrophy (pmoA and $m x a F)$ are detected only at low abundances compared to other genes, with Chan and ToMo showing the highest abundance (Fig. 5a). A complete metabolic pathway for aerobic methanotrophy can only be identified for Gammaproteobacteria (Fig. 6a).

Interestingly, genes related to formate and $\mathrm{CO}$ metabolisms show strong differences between chimney samples. The genes encoding NADP-dependent formate dehydrogenase $(f d h A)$, anaerobic $\mathrm{CO}$ dehydrogenase $(\mathrm{Ni}-$ $\mathrm{CODH} ; \operatorname{coos}$ and $c d h A)$ and acetyl-coenzyme A (CoA) synthase (ACS; $a c s B$ and $c d h C$ ) are particularly enriched in $\mathrm{BaC}$ and PiMo (Fig. 5a). These genes can be involved in carbon fixation through the reductive acetyl-CoA pathway. This pathway is nearly complete for candidate phylum BHI80-139/NPL-UPA2, Chloroflexi, Nitrospirae, and Deltaproteobacteria (Fig. 6a), these lineages being abundant in $\mathrm{BaC}$ and PiMo (Supplementary Fig. S4). In contrast, the NAD-dependent formate dehydrogenaseencoding gene $(f d o G / f d h F)$ is abundant in all samples, with $O C T$ and ToMo showing the highest abundance (Fig. 5a). This gene is detected in all dominant bacterial lineages (Fig. 6b). OCT and ToMo also show a high abundance of coxL gene encoding a $\mathrm{CO}$ dehydrogenase (Mo-CODH) involved in aerobic carboxydotrophy (Fig. 5a). The Mo-CODH-encoding gene is identified in proteobacterial lineages as well as in Chloroflexi (Fig. 6b), which are relatively well represented in $O C T$ and ToMo (Supplementary Fig. S4).

The $r b c L$ gene coding for the ribulose-bisphosphate carboxylase, involved in the aerobic Calvin-Benson-Bassham cycle, is detected in all samples but is dominant in $B a C$, PiMo, and ToMo (Fig. 5a). The Calvin-Benson-Bassham cycle is complete in Alphaproteobacteria and nearly complete in Gammaproteobacteria (Fig. 6a).

\section{Potential sulfur, nitrogen, and oxygen metabolisms}

Although less abundant in $O C T$, the sulfide:quinone oxidoreductase-encoding gene ( $s q r$ ) shows high abundance in all metagenomes, suggesting, along with the ubiquitous 


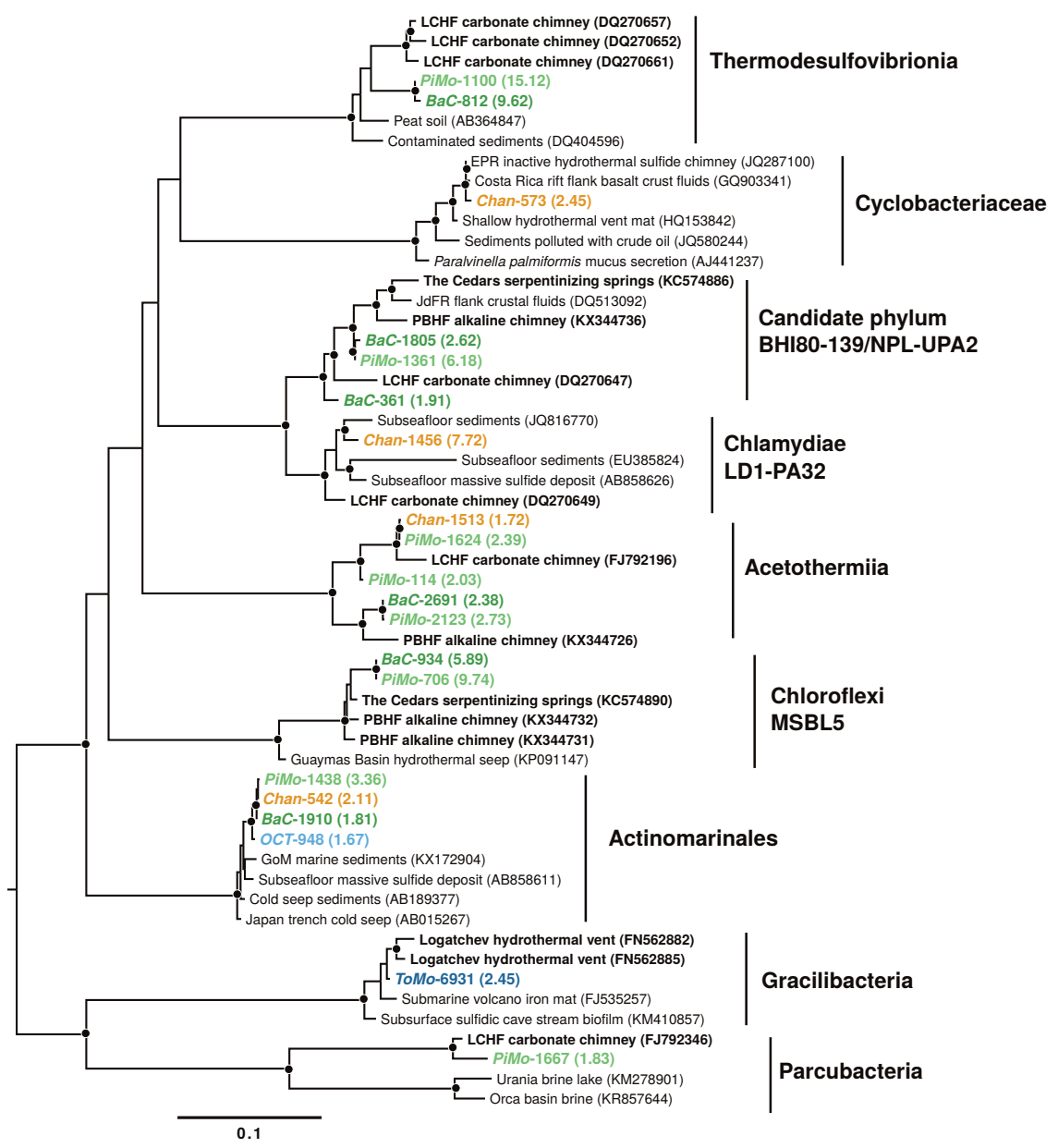

Fig. 4 Maximum likelihood phylogenetic tree of Nitrospirae (Thermodesulfovibrionia), Bacteroidetes (Cyclobacteriaceae), candidate phylum BHI80-139/NPL-UPA2, Chlamydiae, Acetothermia (Acetothermiia), Chloroflexi, Actinobacteria (Actinomarinales) and Patescibacteria (Gracilibacteria and Parcubacteria) based on near full-length 16S rRNA-encoding gene reconstructed from metagenomic reads. To highlight phylotype diversity, only abundant sequences $(>1.5 \%)$ are represented. Sequences from this study are colored with respect to chimney samples (Supplementary Table S1) with normalized

presence of the $\operatorname{sox} Y$ gene, that oxidation of reduced-sulfur species could be an important metabolism in all chimneys (Fig. 5b). The SOX system, involved in thiosulfate oxidation, is detected only in Alpha- and Gammaproteobacteria (Fig. 6a). In contrast, genes potentially involved in dissimilatory sulfate and sulfite reduction ( $a p r A$ and $d s r A)$ and nitrate and nitrite reduction to ammonia $\mathrm{NH}_{3}$ (napA and $n r f A)$ or cytoplasmic nitrate reduction (narG) are enriched in $\mathrm{BaC}$ and PiMo (Fig. 5b). The dissimilatory sulfate reduction pathway is nearly complete for Delta- and Gammaproteobacteria, while the dissimilatory nitrate reduction pathway is complete or nearly complete for all proteobacterial lineages and Nitrospirae (Fig. 6a). The ammonia monooxygenase-encoding gene (amoA) and, to a lesser extent, the hydroxylamine dehydrogenase-encoding gene relative abundance in brackets (\%). Environmental clone accession numbers are indicated in brackets with serpentinization-related ecosystems in bold. They correspond to the closest hits to the near full-length 16S rRNA-encoding gene sequences reported in this study using the SILVA database release 132 [26]. Bootstrap values over $70 \%$ support based on 1,000 replicates are indicated by black dots on their respective nodes. LCHF Lost City hydrothermal field, PBHF Prony Bay hydrothermal field, EPR East Pacific rise, JdFR Juan de Fuca ridge, GoM, Gulf of Mexico.

(hao), involved in nitrification (i.e., ammonia oxidation), are particularly enriched in $O C T$ and ToMo (Fig. 5b). Potential for nitrification is found in Gammaproteobacteria and Thaumarchaeota lineages (Fig. 6a) while the hao gene is not detected in OCHF Thaumarchaeota. The nirK gene is also abundant in $O C T$ and ToMo metagenomes (Fig. 5b). Interestingly, nirK has been identified in Thaumarchaeota, suggesting a potential role of this lineage in nitrogen monoxide-dependent hydroxylamine oxidation [48], in addition to denitrification for other lineages (Fig. 6a).

Genes involved in aerobic respiration are also represented in OCHF metagenomes with predominantly the $c c o N$ gene coding for cytochrome-C oxidase $c b b 3$-type in $\mathrm{BaC}$ and PiMo, while $O C T$ and ToMo are dominated by the cytochrome-C oxidase aa3-type-encoding gene ( $\operatorname{cox} C)$ 

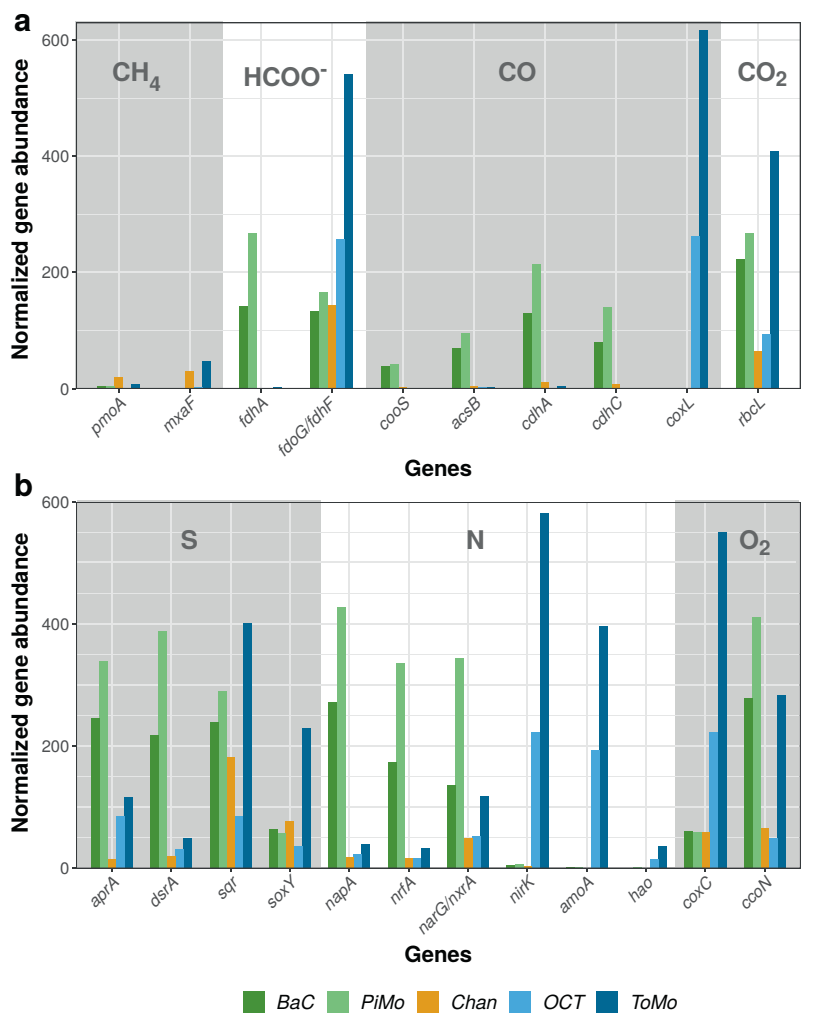

Fig. 5 Normalized abundance of key genes in chimney metagenomes according to PROKKA [39] and KEGG orthology [41] annotations. a Genes involved in $\mathrm{C} 1$ compounds' metabolisms. b Genes involved in sulfur, nitrogen, and oxygen metabolisms. Each gene and its function is described in Supplementary Table S3.

(Fig. 5b). Both genes are present in all proteobacterial lineages and in Thaumarchaeota (Fig. 6).

\section{Potential hydrogen metabolisms}

Genes encoding oxygen sensitive [FeFe]-hydrogenases groups $\mathrm{A}, \mathrm{B}$, and $\mathrm{C}$ are one to two orders of magnitude more abundant in $\mathrm{BaC}$ and $\mathrm{PiMo}$, but also more abundant in Chan compared to $O C T$ and ToMo (Fig. 7). The enzyme and homology annotations of [FeFe]-hydrogenases group A reveal similarities with the $h n d D$ gene coding for $\mathrm{NADP}^{+}$reducing hydrogenases, which may belong to subgroup A3 $[42,43]$. This gene is detected in Euryarchaeota, in the candidate phylum BHI80-139/NPL-UPA2 and in Chloroflexi (Fig. 6b). In contrast, the gene encoding [FeFe]-hydrogenases group B shows similarities with the hydA gene and is only observed in Chloroflexi (Fig. 6b).

Apart from the oxygen tolerant subgroups $3 b$ and $3 d$ involved in the reversible oxidation of $\mathrm{H}_{2}$, genes encoding [NiFe]-hydrogenases, including those involved in anaerobic uptake of $\mathrm{H}_{2}$, are one order of magnitude less abundant in OCHF metagenomes compared to [FeFe]-hydrogenaseencoding genes (Fig. 7). The hox gene encoding [NiFe]hydrogenases subgroup $3 \mathrm{~d}$ is found in Chloroflexi, and
Alpha- and Gammaproteobacteria (Fig. 6b). Genes coding for [ $\mathrm{NiFe}]$-hydrogenases subgroups $3 \mathrm{a}$ and $3 \mathrm{~b}$, involved in hydrogenotrophic methanogenesis, are scarce in all metagenomes and relate to Chloroflexi and Deltaproteobacteria (Figs. 6b and 7).

\section{Carbon oxidation state of predicted proteomes}

All OCHF predicted proteomes are, on average, relatively reduced compared to $Z_{\mathrm{C}}$ values calculated for predicted proteomes from ambient seawater near the Axial seamount, north east Pacific Ocean, but more oxidized than the proteomes predicted for LCHF chimneys [44] (Fig. 8). Nevertheless, $Z_{C}$ mean values and variances differ significantly from sample to sample. In contrast to their microbial diversity and metabolic potential, $Z_{C}$ mean values and variances of $B a C$ and PiMo $(-0.1752 \pm 0.010$ and $-0.1653 \pm 0.011$, respectively) are significantly different $(p<0.001)$. Chan (mean $Z_{C}=-0.1753 \pm 0.009$ ) and $B a C$ show highly similar $(p=0.914)$ reduced proteomes compared to other samples $(p<0.001)$. OCT and ToMo predicted proteomes are significantly more oxidized (mean $Z_{\mathrm{C}}=-0.1620 \pm 0.007$ and $-0.1609 \pm 0.008$, respectively) and similar $(p=0.310)$, while being different from PiMo ( $p=0.015$ and 0.002 for $O C T$ and ToMo, respectively).

\section{Discussion}

\section{Environmental conditions}

At OCHF, no focused hydrothermal discharges in the form of plumes or shimmering fluids have been observed, suggesting that the hydrothermal fluid flow is extremely slow and diffuse. This diffuse flow made it impossible with the equipment available during the ROVSMOOTH cruise to sample endmember hydrothermal fluid properly without seawater influence [49]. Nevertheless, fluids sampled close to putative chimney fluid outlets reveal slightly higher $\mathrm{pH}$ values than ambient seawater near vents associated with ultramafic rocks [50] and hydrothermal fluids of the serpentinization-related Von Damm, Rainbow, or Logatchev hydrothermal fields [3] (Supplementary Table S4). Although lower than $\mathrm{pH}$ values measured at LCHF, PBHF and other alkaline serpentinitehosted ecosystems [3], these $\mathrm{pH}$ values, as well as the presence of brucite and carbonate chimneys, highlight the alkaline nature of Old City hydrothermal fluids. Their slight enrichment in $\mathrm{Mg}, \mathrm{Ca}, \mathrm{Na}$, and $\mathrm{Li}$ compared to standard seawater (Supplementary Table S4) could be related to the dissolution of brucite and carbonate minerals during sampling or to the influence of alkaline hydrothermal fluids [9].

Like LCHF, PBHF and the Mariana forearc Shinkai Seep $[6,8,9,16]$, most of the OCHF chimney samples are 
Fig. 6 Overview of metabolic pathways' completion and of the presence of key enzymeencoding genes in dominant microbial lineages of chimney metagenomes. Colored boxes highlight the presence and completion of metabolic pathways (a) or key genes coding for the enzyme indicated (b) as determined from KEGG module and orthology [41]. Metabolic pathway that are missing half of all required genes are considered undetected. Nitrogen fixation and methanogenesis are not indicated due to their absence or poor completion in all microbial lineages investigated. a

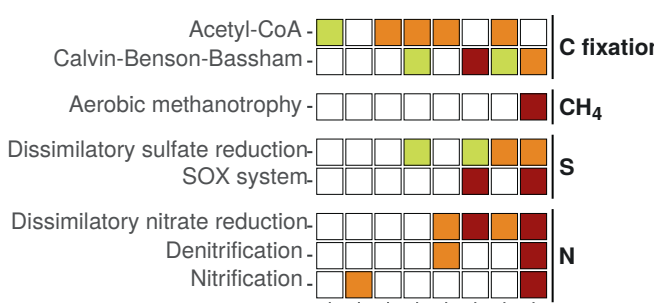

Complete

1 enzyme missing

2 enzymes missing

Not detected b

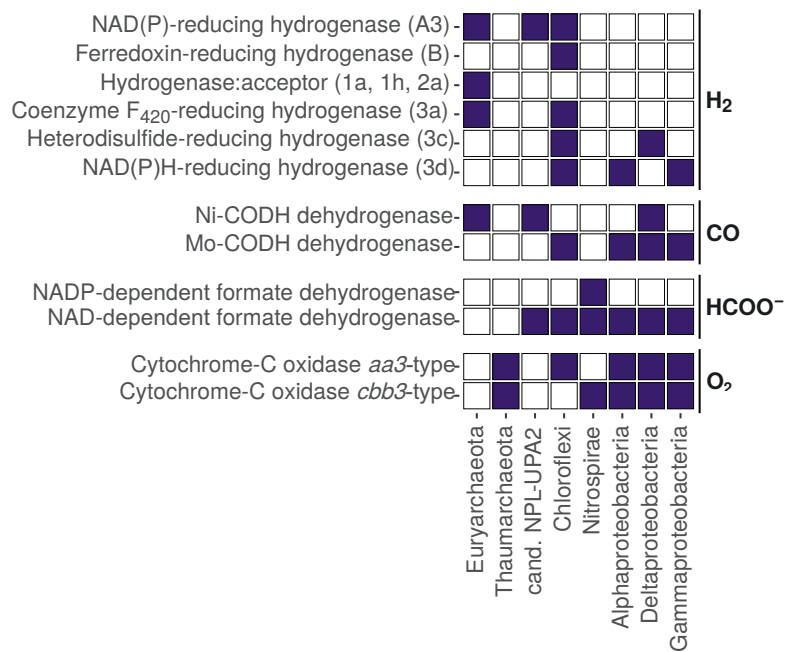

Present

Not detected

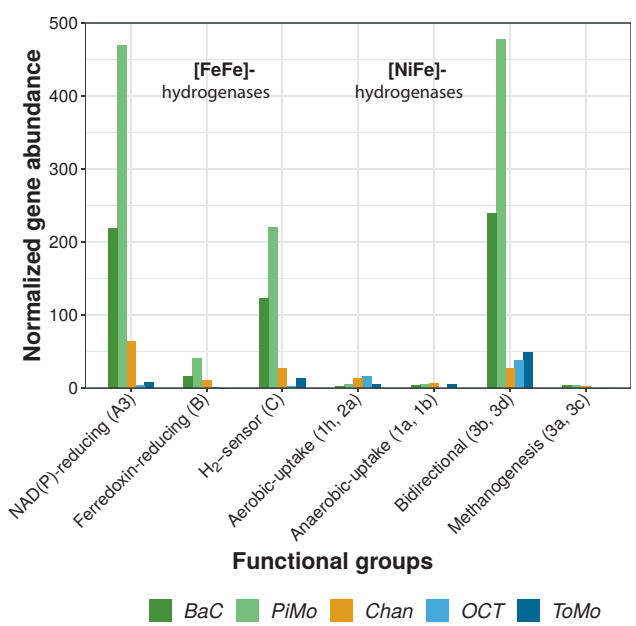

Fig. 7 Normalized abundance of genes encoding hydrogenases. The different groups or subgroups $[42,43]$ are identified in brackets. Each group of hydrogenases identified in our metagenomic data and its functions is described in Supplementary Table S3.

mainly composed of brucite with minor aragonite and/or calcite (Fig. 2). Since brucite is only stable at $\mathrm{pH}$ above 10 [9], ref. [51] proposed that LCHF chimneys should initially consist of brucite and aragonite, gradually replaced by calcite as hydrothermal activity decreases and seawater influence increases. The increasing influence of seawater

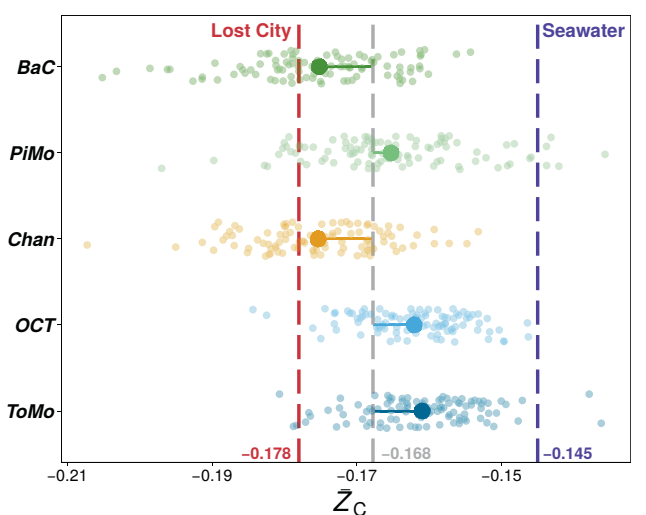

Fig. 8 Distribution of average carbon oxidation state $\left(Z_{C}\right)$ estimated for the subsampled proteins predicted from metagenomes. For each chimney sample, the vertical distribution was artificially computed to avoid overlap. The gray dashed vertical line highlights mean $Z_{\mathrm{C}}$ value $(-0.168)$ obtained at $\mathrm{OCHF}$ for all metagenomes and dark dots indicate the mean $Z_{\mathrm{C}}$ value for each predicted proteome with distance from the mean $Z_{C}$ value. $Z_{C}$ values calculated by [44] for Lost City hydrothermal chimneys (red dashed line) and ambient seawater near the Axial seamount, north east Pacific Ocean (blue dashed line), are indicated for comparison. Cand. candidate phylum.

causes a decrease in fluid $\mathrm{pH}$, hence dissolving brucite. The resulting increase in $\mathrm{pH}$ causes carbonate ions from seawater to precipitate with divalent cations such as $\mathrm{Ca}^{2+}$ and $\mathrm{Mg}^{2+}$ from hydrothermal fluids or seawater. This is 
consistent with the dark coating made of biological mats and manganese deposits reported for ToMo and PiMo chimneys (Fig. 1), suggesting that these may be less active compared to the whitish, porous, and friable structures associated with recent hydrothermal deposits that characterize active chimneys $[10,16]$. Indeed, these samples contain higher relative proportions of calcium carbonates than the other chimney samples that are dominated by brucite. However, while brucite in absent from ToMo, its high relative content in PiMo suggests that this chimney is still active, as also supported by its microbial community composition.

Overall, the mineralogy of our samples, indicative of exposure to hydrothermal fluid versus seawater chemistry, suggests that recent mineral deposits where brucite dominates could have been formed from discharging alkaline hydrothermal fluids. In addition, the dominance of brucite could indicate a higher $\mathrm{pH}$ for the hydrothermal fluids compared to the values reported in Supplementary Table S4.

\section{Variability of local environmental conditions in chimneys}

Recent studies have shown a strong correlation between the decrease in $Z_{C}$ values of predicted proteomes and increased alkaline and reducing conditions [44, 52]. As observed in sediments and other hydrothermal fields [53, 54], the diffuse fluid flow at OCHF can lead to highly heterogeneous geochemical conditions with mixed but variable influences of reducing hydrothermal fluids and oxygenated seawater intrusions, and thus to variable $Z_{C}$ values. This is consistent with the carbon oxidation state estimated for OCHF chimneys from predicted proteomes that shows significant variability within and between samples (Fig. 8). This highlights different environmental conditions at the chimney scale or across the entire hydrothermal field. Compared to $Z_{C}$ values of predicted proteomes from ambient seawater near hydrothermal vents [44], the $Z_{C}$ values estimated for OCHF are lower (Fig. 8), overall suggesting more reducing and alkaline conditions on average. These reducing and alkaline conditions are consistent with the predictions made above from the mineralogy, except for $O C T$ which has $Z_{C}$ values similar to those of ToMo despite a higher relative content in brucite. This suggests for $O C T$ a greater influence of seawater intrusions than in other chimney samples. $O C T$ was sampled at the top of the OCHF tallest chimney (i.e., $52 \mathrm{~m}$ above seafloor) and is located away from the other sampled chimneys. This raises questions about the influence of vent geographical distribution as well as subseafloor architecture and associated hydrodynamics on chimney microbial ecology and prevailing environmental conditions.

\section{Methane metabolisms}

Potential methanogenic Archaea (i.e., Methanosarcinales) are less represented in the studied chimneys than Bacteria (Supplementary Fig. S4). Moreover, complete methanogenesis pathways are missing in OCHF Euryarchaeota. Although these results could be attributed to the limitations of LCA annotations, methanogens may not be dominant at OCHF. This recalls ophiolite ecosystems where potential methanogenic archaea are generally rare or absent, whereas they flourish within active LCHF chimneys [11, 55-57]. Nevertheless, our study covers only a small portion of chimneys and we cannot exclude the possibility that Methanosarcinales are present at higher abundance than what we observe at OCHF.

Interestingly, Chan presents the most reduced predicted proteomes (Fig. 8). This sample is dominated by potential aerobic methane- or methyl-oxidizing bacteria, such as Methyloprofundus, which may appear as diplococci in Chan samples (Fig. 3e) [58]. This is supported by the highest abundance in Chan metagenome of genes involved in aerobic methanotrophy ( $p m o A$ and $m x a F$ ), and by the fact that complete aerobic methane oxidation pathway is only found in Gammaproteobacteria, which also dominate Chan microbial community (Figs. 5 and 6 and Supplementary Fig. S4). Potential aerobic methanotrophs among Methylococcaceae have been reported in several oceanic and ophiolitic serpentinite-hosted ecosystems, including LCHF [11, 55-57]. Although this microbial lineage requires oxygen from seawater, it may also be sustained at OCHF by reduced carbon sources including methane potentially derived from abiotic organic synthesis associated with serpentinizing environments and leading to reduced proteomes, as observed for Chan.

\section{Carbon monoxide and formate metabolisms}

Like methane, $\mathrm{CO}$ and formate can also derive from abiotic organic synthesis promoted in such environments [59, 60]. Since $\mathrm{CO}_{2}$ is usually depleted in low-temperature serpentinization-influenced hydrothermal fluids due to the associated alkaline $\mathrm{pH}$ [3], both abiotic $\mathrm{CO}$ and formate can represent valuable alternative electron donors and carbon sources. Genes involved in anaerobic or aerobic CO- and formatebased metabolisms are abundant in OCHF metagenomes but they show different profiles between samples (Fig. 5a) suggesting different utilization of $\mathrm{CO}$ and formate. While $\mathrm{BaC}$ and PiMo are enriched in genes coding for anaerobic NiCODH ( $\operatorname{coos}$ or $c d h A)$ and NADP-dependent formate dehydrogenase (fdhA), OCT and ToMo metagenomes show high abundance of coxL gene coding for aerobic Mo-CODH, in agreement with the associated microbial ecology. As proposed for the Samail ophiolite [52], this may be related to the different environmental conditions (i.e., redox and $\mathrm{pH}$ ) that prevail in OCHF chimneys (e.g., Fig. 8). 
The NAD-dependent formate dehydrogenase-encoding gene $(f d o G / f d h F)$ is abundant in all samples (Fig. 5a) and is widespread among OCHF bacterial lineages (Fig. 6) pointing to formate to be an important electron donor at OCHF. It should be noted that NAD-dependent formate dehydrogenase could serve as an alternative to the NADPdependent formate dehydrogenase in putative acetogens [61]. Moreover, together with genes encoding acetyl-CoA synthase $(a c s B$ or $c d h C)$, the $\mathrm{Ni}-\mathrm{CODH}$-encoding genes are known to be involved in acetogenesis through the carbonyl branch of the oxidative or reductive acetyl-CoA pathway [62]. The abundance of Ni-CODH-encoding genes in $\mathrm{BaC}$ and PiMo (Fig. 5a) suggests high metabolic potential for COutilizing acetogenesis that could be related to the candidate phylum BHI80-139/NPL-UPA2, Chloroflexi, Nitrospirae, and Deltaproteobacteria (Fig. 6), all of which being abundant in these chimneys. These taxa are associated with LCHF, PBHF, or The Cedars phylotypes (Fig. 4 and Supplementary Fig. S6), overall suggesting that acetogenic bacteria could be widespread in serpentinite-hosted ecosystems. Nevertheless, the Ni-CODH-encoding gene ( $\operatorname{cooS}$ or $c d h A)$ is not detected in OCHF Chloroflexi and Nitrospirae. Like for the lack of genes for methanogenesis, it could be explained by the poor specificity of LCA taxonomic annotation.

Conversely, coxL coding for a Mo-CODH involved in aerobic oxidation of $\mathrm{CO}$ is abundant in OCT and ToMo metagenomes (Fig. 5a). It has been reported for the Tablelands ophiolite (Canada) that $\mathrm{CO}$ carried by serpentinization-derived reducing fluids could serve as electron donor rather than for biomass synthesis when mixing with oxidized surface waters [63]. Accordingly, CO may represent a valuable electron donor in $O C T$ and ToMo chimneys where coxL is abundantly detected in all proteobacterial lineages, with Alpha- and Gammaproteobacteria being abundant, and in Chloroflexi (Fig. 6). This is consistent with the low abundance of putative acetogens and the significantly higher $Z_{C}$ values estimated for $O C T$ and ToMo compared to other chimneys (Fig. 8), overall suggesting that in OCT and ToMo, in addition to formate, $\mathrm{CO}$ could be oxidized by dominant Alpha- and/or Gammaproteobacteria rather than being used as carbon source for acetogenesis as in $\mathrm{BaC}$ and PiMo.

\section{Hydrogenases and potential microbial adaptation}

As $\mathrm{H}_{2}$ solubility and mobility decreases with salinity and lower temperature [64], an increased influence of seawater intrusions, supported by the mineralogy of these chimneys, may lead to the depleted abundance in hydrogenases observed in OCT and ToMo (Fig. 7). Conversely, genes encoding $[\mathrm{FeFe}]$-hydrogenases group A3 (hndD) and [NiFe]-hydrogenases groups $3 \mathrm{~b}$ and $3 \mathrm{~d}$ (hoxH) are particularly enriched in $\mathrm{BaC}$ and PiMo where a high metabolic potential for acetogenesis related to candidate phylum BHI80-139/NPL-UPA2, Chloroflexi, Nitrospirae, and Deltaproteobacteria has been suggested. [FeFe]-hydrogenase group A3 could be associated with acetogenesis by providing reduced NADH and ferredoxin from the oxidation of $\mathrm{H}_{2}$ [43, 65]. Genes encoding [FeFe]-hydrogenases group A3 are consistently found in some of the potential acetogens dominating in $\mathrm{BaC}$ and PiMo and in Euryarchaeota (Fig. 6). Although no hydrogenase-encoding genes has been reported in the genome of the candidate phylum BHI80-139/NPL-UPA2 retrieved at The Cedars [66], it should be noted that hndD presents homologies with the nuoF gene coding for a subunit of the respiratory complex I and identified in this genome [65]. Given that certain hydrogenases have been proposed as potential precursors of this complex [67] and that it is unlikely that the genome of the candidate phylum BHI80-139/NPL-UPA2 encodes a complete respiratory complex I, we suggest that the identified nиоF gene may instead encode a [FeFe]hydrogenases group A3, hence supporting acetogenic pathway for candidate phylum BHI80-139/NPL-UPA2.

[NiFe]-hydrogenases groups $3 \mathrm{~b}$ and $3 \mathrm{~d}$ have been proposed to serve as an electron valve to regulate intracellular oxidation state [43]. Under anoxic reducing conditions, these hydrogenases can be involved in $\mathrm{H}_{2}$ fermentative evolution from NAD $(\mathrm{P}) \mathrm{H}$ produced, for example, by formate oxidation. Under oxic conditions, they are associated with $\mathrm{H}_{2}$ uptake for energy production, in association with the respiratory complex I, or with biosynthesis, which requires $\mathrm{NAD}(\mathrm{P}) \mathrm{H}$ [67]. [NiFe]-hydrogenases groups $3 \mathrm{~b}$ and $3 \mathrm{~d}$ could therefore be versatile enough to cope with variable mixing of reducing hydrothermal fluids and oxygenated seawater. At OCHT, [NiFe]-hydrogenase groups $3 \mathrm{~b}$ and $3 \mathrm{~d}$ are detected in Chloroflexi phylotypes (Fig. 6), which group with Chloroflexi from PBHF and The Cedars (Fig. 4), two sites characterized by strongly reducing conditions where these phylotypes are also abundant [13, 14, 19]. Moreover, [NiFe]-hydrogenaseencoding genes were also detected in reconstructed genomes of LCHF Chloroflexi [68]. These [NiFe]-hydrogenasesencoding genes are also found in OCHF Alpha- and Gammaproteobacteria (Fig. 6). Formate dehydrogenase-encoding genes and nearly complete Calvin-Benson-Bassham cycle are also detected in these lineages, suggesting that $\mathrm{OCHF}$ Alpha- and Gammaproteobacteria may have the metabolic potential for fermentative formate oxidation as well as $\mathrm{CO}_{2}$ fixation with $\mathrm{H}_{2}$ oxidation [69].

\section{Other metabolisms}

At LCHF, the exterior of less active or inactive chimneys is dominated by Proteobacteria that metabolize oxidized compounds derived from seawater (i.e., $\mathrm{O}_{2}, \mathrm{CO}_{2}$, sulfate, and nitrate) [10, 11]. Similarly, at OCHF, proteobacterial 
lineages show metabolic capabilities for aerobic respiration, $\mathrm{CO}_{2}$ fixation through the Calvin-Benson-Bassham cycle, as well as sulfur and nitrogen metabolisms (Fig. 6). The abundance of Deltaproteobacteria and genes involved in dissimilatory sulfate reduction in $\mathrm{BaC}$ and PiMo (Fig. 5b and Supplementary Fig. S4) suggest that this metabolism dominates in these chimney samples. However, it should be noted that genes involved in dissimilatory sulfate reduction could mediate the reverse reaction, i.e., sulfur oxidation to sulfate likely to be operated by Alpha- and Gammaproteobacteria, considering that the SOX system is complete in these lineages (Fig. 6). In addition to sulfate contained in seawater $[10,11]$, sulfate may also be enriched in hydrothermal fluids due to extensive subseafloor circulation of oxidized seawater during peridotite exhumation, which could lead to local oxidation of sulfides [70]. Sulfuroxidizing bacteria, such as aerobic proteobacterial Rhodobacterales, Thiomicrospirales, Thiotrichales (Fig. 2 and Supplementary Fig. S3) and related metabolic genes are widespread in all OCHF chimney samples. Most of these lineages are also common to LCHF (Supplementary Fig. S5 and S6). Reduced-sulfur compounds could be possibly derived from both biotic (i.e., from sulfate reducing bacteria) or abiotic components in the hydrothermal fluid.

Both Nitrospirae and Gammaproteobacteria could be involved in nitrate reduction through dissimilatory nitrate reduction or denitrification (Fig. 6). However, although such metabolisms have been reported to be possible in other serpentinite-hosted ecosystems [55-57], a low concentration of nitrate is usually documented in such systems. $O C T$ and ToMo are dominated by Thaumarchaeota, which are more likely to originate from deep seawater where they are widespread [71], than from hydrothermal fluids. The relative enrichment in ammonia monooxygenase-encoding genes (amoA) in OCT and ToMo suggests that Thaumarchaeota could be involved in aerobic ammonia oxidation. OCHF Thaumarchaeota likely use the nitrite reductase (encoded by nirK) of the nitrogen monoxide-dependent ammonia oxidation pathway [48], since they lack the hydroxylamine dehydrogenase-encoding gene (hao).

\section{Conclusion}

Using an integrated approach, we provide the first description of the microbial ecology of the recently discovered Old City hydrothermal field. So far, this site represents the first 'Lost City'-type hydrothermal field observed along mid-ocean ridges. Therefore, OCHF is of particular interest to improve our understanding of ecosystems supported by oceanic serpentinization.

Despite the lack of environmental data, our results provide indirect evidences for slow and diffuse discharge of alkaline and reducing hydrothermal fluids at OCHF (i.e., characteristic carbonate-brucite assemblages forming chimneys, reduced predicted proteomes, potential anaerobic metabolisms involving various types of hydrogenases and the predominance of putative acetogens and formate- and CO-utilizing bacteria, among others). Dominant taxa and metabolisms vary between chimneys, in conjunction with the local redox state $( \pm \mathrm{pH})$ evaluated from predicted proteomes. CO- and formate-based metabolisms are widespread, although $\mathrm{CO}$ and formate utilization as carbon or electron sources and related taxa may strongly differ from chimney to chimney. Although we provide a first insight into the metabolic capabilities and putative environmental conditions at OCHF, our study was hampered by technical limitations inherent to the unexpected discovery of deep oceanic hydrothermal sites. However, there is no doubt that future explorations and studies will give a better constrain of the metabolic potential of microbial lineages. We therefore encourage further investigations of this unique site, which could strongly improve our understanding of microbial ecology related to serpentinization. OCHF discovery also suggests that active 'Lost City'-type hydrothermal fields could be more widespread on the seafloor than previously documented along mid-ocean ridges.

Acknowledgements The authors express their deep appreciation to the crew of R/V Pourquoi pas? and to the Genavir engineers in charge of the ROV Victor 6000 operations. They are also grateful to the scientific party of the ROVSMOOTH cruise and to shore-based collaborators. The authors thank Hilary Morrison, Aleksey Morozov, and Nicole Robichaud (Marine Biological Laboratory, Woods Hole Oceanographic Institution, MA, USA) for performing the DNA sequencing, as well as Sophie Nowak (Plateforme Rayons X, Université de Paris, France) and Pierre Burckel (IPGP, France) who performed the XRD and ICP-MS analyses, respectively. Sequencing was supported by the Census of Deep Life of the Deep Carbon Observatory funded by the Alfred P. Sloan Foundation. This study also received financial support from the French National Agency For Research (ANR) through the deepOASES project (ANR-14-CE01-0008-01), the "Mission pour les Initiatives Transverses et Interdisciplinaires" of the French CNRS (Défi Origines 2018) and the LABEX UnivEarthS. This work was supported by the IPGP multidisciplinary program PARI and by Région Ile-de-France SESAME grant No. 12015908. Finally, the authors would like to thank the French Institute of Bioinformatics (IFB, ANR-11-INBS-0013) for providing storage and computing resources on its national life science cloud. This study contributes to the IdEx Université de Paris ANR-18-IDEX-0001.

Author contributions BM, MC, and EG designed the study. MC and AL carried out the field sampling. AL performed the DNA extractions and data analysis. BM, EG, and AL contributed equally to the microimaging. VC performed the fluid analyses. BM, EG, MC, and $\mathrm{VC}$ contributed to data interpretation. AL wrote the manuscript with contributions from all authors.

\section{Compliance with ethical standards}

Conflict of interest The authors declare that they have no conflict of interest. 
Publisher's note Springer Nature remains neutral with regard to jurisdictional claims in published maps and institutional affiliations.

Open Access This article is licensed under a Creative Commons Attribution 4.0 International License, which permits use, sharing, adaptation, distribution and reproduction in any medium or format, as long as you give appropriate credit to the original author(s) and the source, provide a link to the Creative Commons license, and indicate if changes were made. The images or other third party material in this article are included in the article's Creative Commons license, unless indicated otherwise in a credit line to the material. If material is not included in the article's Creative Commons license and your intended use is not permitted by statutory regulation or exceeds the permitted use, you will need to obtain permission directly from the copyright holder. To view a copy of this license, visit http://creativecommons. org/licenses/by/4.0/.

\section{References}

1. Proskurowski G, Lilley MD, Seewald JS, Früh-Green GL, Olson EJ, Lupton JE, et al. Abiogenic hydrocarbon production at Lost City hydrothermal field. Science. 2008;319:604-7.

2. Kelley DS, Lilley MD, Früh-Green GL. Volatiles in submarine environments: food for life. In: Wilcock WSD, Delong EF, Kelley DS, Baross JA, Cary SC, editors. The subseafloor biosphere at mid-ocean ridges. Geophysical monograph, vol 144. Washington DC: American Geophysical Union; 2004. p. 167-89.

3. Schrenk MO, Brazelton WJ, Lang SQ. Serpentinization, carbon, and deep life. In: Hazen RM, Jones AP, Baross JA, editors. Carbon in earth. Reviews in mineralogy and geochemistry, vol 75. Chantilly, VA: Mineralogical Society of America; 2013. p. 575-606.

4. Cannat M, Mével C, Maia M, Deplus C, Durand C, Gente P, et al. Thin crust, ultramafic exposures, and rugged faulting patterns at the Mid-Atlantic Ridge $\left(22^{\circ}-24^{\circ} \mathrm{N}\right)$. Geology. 1995;23:49-52.

5. Cannat M, Sauter D, Mendel V, Ruellan E, Okino K, Escartin J, et al. Modes of seafloor generation at a melt-poor ultraslowspreading ridge. Geology. 2006;34:605-8.

6. Kelley DS, Karson JA, Früh-Green GL, Yoerger DR, Shank TM, Butterfield DA, et al. A serpentinite-hosted ecosystem: the Lost City hydrothermal field. Science. 2005;307:1428-34.

7. Seyfried WEJ, Pester NJ, Tutolo BM, Ding K. The Lost City hydrothermal system: constraints imposed by vent fluid chemistry and reaction path models on subseafloor heat and mass transfer processes. Geochim Cosmoschim Acta. 2015;163:59-79.

8. Okumura T, Ohara Y, Stern RJ, Yamanaka T, Onishi Y, Watanabe $\mathrm{H}$, et al. Brucite chimney formation and carbonate alteration at the Shinkai Seep Field, a serpentinite-hosted vent system in the southern Mariana forearc. Geochem Geophys Geosy. 2016;17: 3775-96.

9. Monnin C, Chavagnac V, Boulart C, Ménez B, Gérard M, Gérard $\mathrm{E}$, et al. Fluid chemistry of the low temperature hyperalkaline hydrothermal system of Prony Bay (New Caledonia). Biogeosciences. 2014;11:5687-706.

10. Schrenk MO, Kelley DS, Bolton SA, Baross JA. Low archaeal diversity linked to subseafloor geochemical processes at the Lost City hydrothermal field, Mid-Atlantic Ridge. Environ Microbiol. 2004;6:1086-95.

11. Brazelton WJ, Schrenk MO, Kelley DS, Baross JA. Methane- and sulfur-metabolizing microbial communities dominate the Lost City hydrothermal field ecosystem. Appl Environ Microbiol. 2006;72:6257-70.

12. Brazelton WJ, Ludwig KA, Sogin ML, Andreishcheva EN, Kelley $\mathrm{DS}$, Shen $\mathrm{C}-\mathrm{C}$, et al. Archaea and bacteria with surprising microdiversity show shifts in dominance over 1,000-year time scales in hydrothermal chimneys. Proc Natl Acad Sci USA. 2010;107:1612-7.

13. Quéméneur M, Bes M, Postec A, Mei N, Hamelin J, Monnin C, et al. Spatial distribution of microbial communities in the shallow submarine alkaline hydrothermal field of the Prony Bay, New Caledonia. Environ Microbiol Rep. 2014;6:665-74.

14. Postec A, Quéméneur M, Bes M, Mei N, Benaïssa F, Payri C, et al. Microbial diversity in a submarine carbonate edifice from the serpentinizing hydrothermal system of the Prony Bay (New Caledonia) over a 6-year period. Front Microbiol. 2015;6:857.

15. Frouin E, Bes M, Ollivier B, Quéméneur M, Postec A, Debroas D, et al. Diversity of rare and abundant prokaryotic phylotypes in the Prony hydrothermal field and comparison with other serpentinitehosted ecosystems. Front Microbiol. 2018;9:102.

16. Pisapia C, Gérard E, Gérard M, Lecourt L, Lang SQ, Pelletier B, et al. Mineralizing filamentous bacteria from the Prony bay hydrothermal field give new insights into the functioning of serpentinization-based subseafloor ecosystems. Front Microbiol. 2017;8:57.

17. Brazelton WJ, Nelson B, Schrenk MO. Metagenomic evidence for $\mathrm{H}_{2}$ oxidation and $\mathrm{H}_{2}$ production by serpentinite-hosted subsurface microbial communities. Front Microbiol. 2012;2:268.

18. Brazelton WJ, Mehta MP, Kelley DS, Baross JA. Physiological differentiation within a single-species biofilm fueled by serpentinization. mBio. 2011;2:e00127-11.

19. Suzuki S, Ishii S, Wu A, Cheung A, Tenney A, Wanger G, et al. Microbial diversity in The Cedars, an ultrabasic, ultrareducing, and low salinity serpentinizing ecosystem. Proc Natl Acad Sci USA. 2013;110:15336-41.

20. Cannat M, Agrinier P, Martinez I, Vitale Brovarone A, Lecoeuvre A, Corre M, et al. A forest of carbonate-brucite chimneys at the southwest Indian ridge: the ultramafic-hosted Old City hydrothermal field. Goldschmidt Abstracts. 2019:2019;463.

21. Lecoeuvre A, Ménez B, Lecourt L, Gérard E. Microbial ecology linked to serpentinization processes and related carbonation at the Old City hydrothermal field. Goldschmidt Abstracts. 2018;2018:1428.

22. Sauter D, Cannat M, Rouméjon S, Andreani M, Birot D, Bronner A, et al. Continuous exhumation of mantle-derived rocks at the southwest Indian Ridge for 11 million years. Nat Geosci. 2013;6: 314-20.

23. Eren AM, Morrison HG, Lescault PJ, Reveillaud J, Vineis JH, Sogin ML. Minimum entropy decomposition: Unsupervised oligotyping for sensitive partitioning of high-throughput marker gene sequences. ISME J. 2015;9:968-79.

24. Wright ES, Yilmaz LS, Noguera DR. DECIPHER, a search-based approach to chimera identification for 16S rRNA sequences. Appl Environ Microbiol. 2012;78:717-25.

25. Wright ES. Using DECIPHER v2 0 Anal big Biol sequence data R. R J. 2016;8:352-9.

26. Quast C, Pruesse E, Yilmaz P, Gerken J, Schweer T, Yarza P, et al. The SILVA ribosomal RNA gene database project: improved data processing and web-based tools. Nucleic Acids Res. 2013;41:D590-6.

27. Sheik CS, Reese BK, Twing KI, Sylvan JB, Grim SL, Schrenk $\mathrm{MO}$, et al. Identification and removal of contaminant sequences from ribosomal gene databases: lessons from the census of deep life. Front Microbiol. 2018;9:840.

28. Wickham H, editor. ggplot2: elegant graphics for data analysis. New York: Springer-Verlag; 2016.

29. Paulson JN, Stine OC, Bravo HC, Pop M. Differential abundance analysis for microbial marker-gene surveys. Nat Methods. 2013;10:1200-2.

30. Oksanen J, Blanchet FG, Friendly M, Kindt R, Legendre P, McGlinn $\mathrm{D}$, et al. vegan: community ecology package. $\mathrm{R}$ package version 2.5-5. 2019. https://CRAN.R-project.org/package=vegan. 
31. Li D, Liu C-M, Luo R, Sadakane K, Lam T-W. MEGAHIT: an ultra-fast single-node solution for large and complex metagenomics assembly via succinct de Bruijn graph. Bioinformatics. 2015;31:1674-6.

32. Langmead B, Salzberg SL. Fast gapped-read alignment with Bowtie 2. Nat Methods. 2012;9:357-9.

33. Liao Y, Smyth GK, Shi W. The R package Rsubread is easier, faster, cheaper and better for alignment and quantification of RNA sequencing reads. Nucleic Acids Res. 2019;47:e47.

34. Robinson MD, McCarthy DJ, Smyth GK. edgeR: a bioconductor package for differential expression analysis of digital gene expression data. Bioinformatics. 2010;26:139-40.

35. Buchfink B, Xie C, Huson DH. Fast and sensitive protein alignment using DIAMOND. Nat Methods. 2015;12:59-60.

36. Huson DH, Beier S, Flade I, Górska A, El-Hadidi M, Mitra S, et al. MEGAN community edition - Interactive exploration and analysis of large-scale microbiome sequencing data. PLoS Comput Biol. 2016;12:e1004957.

37. Suzuki S, Ishii S, Hoshino T, Rietze A, Tenney A, Morrill PL, et al. Unusual metabolic diversity of hyperalkaliphilic microbial communities associated with subterranean serpentinization at The Cedars. ISME J. 2017;11:2584-98.

38. Creevey CJ, Doerks T, Fitzpatrick DA, Raes J, Bork P. Universally distributed single-copy genes indicate a constant rate of horizontal transfer. PLoS ONE. 2011;6:e22099.

39. Seemann T. Prokka: rapid prokaryotic genome annotation. Bioinformatics. 2014;30:2068-9.

40. Hyatt D, Chen G-L, Locascio PF, Land ML, Larimer FW, Hauser LJ. Prodigal: prokaryotic gene recognition and translation initiation site identification. BMC Bioinform. 2010;11:119.

41. Kanehisa M, Sato Y, Morishima K. BlastKOALA and GhostKOALA: KEGG tools for functional characterization of genome and metagenome sequences. J Mol Biol. 2016;428:726-31.

42. Boyd ES, Schut GJ, Adams MWW, Peters JW. Hydrogen metabolism and the evolution of biological respiration: Two separate families of enzymes that oxidize hydrogen and also produce it arose through convergent evolution. Microbe Mag. 2014;9:361-7.

43. Greening C, Biswas A, Carere CR, Jackson CJ, Taylor MC, Stott $\mathrm{MB}$, et al. Genomic and metagenomic surveys of hydrogenase distribution indicate $\mathrm{H}_{2}$ is a widely utilised energy source for microbial growth and survival. ISME J. 2016;10:761-77.

44. Dick JM, Yu M, Tan J, Lu A. Changes in carbon oxidation state of metagenomes along geochemical redox gradients. Front Microbiol. 2019;10:120.

45. Dick JM. Calculation of the relative metastabilities of proteins using the CHNOSZ software package. Geochem Trans. 2008; 9:10.

46. Nie L, Wu G, Zhang W. Correlation between mRNA and protein abundance in Desulfovibrio vulgaris: a multiple regression to identify sources of variations. Biochem Biophys Res Commun. 2006;339:603-10.

47. Galambos D, Anderson RE, Reveillaud J, Huber JA. Genomeresolved metagenomics and metatranscriptomics reveal niche differentiation in functionally redundant microbial communities at deep-sea hydrothermal vents. Environ Microbiol. 2019;21: 4395-410.

48. Kozlowski JA, Stieglmeier M, Schleper C, Klotz MG, Stein LY. Pathways and key intermediates required for obligate aerobic ammonia-dependent chemolithotrophy in bacteria and Thaumarchaeota. ISME J. 2016;10:1836-45.

49. Le Bris N, Yücel M, Das A, Sievert SM, LokaBharathi P, Girguis PR. Hydrothermal energy transfer and organic carbon production at the deep seafloor. Front Mar Sci. 2019;5:531.

50. Charlou JL, Donval JP, Fouquet Y, Jean-Baptiste P, Holm N. Geochemistry of high $\mathrm{H}_{2}$ and $\mathrm{CH}_{4}$ vent fluids issuing from ultramafic rocks at the Rainbow hydrothermal field $\left(36^{\circ} 14^{\prime} \mathrm{N}\right.$, MAR). Chem Geol. 2002;191:345-59.

51. Ludwig KA, Kelley DS, Butterfield DA, Nelson BK, Früh-Green G. Formation and evolution of carbonate chimneys at the Lost City hydrothermal field. Geochim Cosmochim Acta. 2006;70: 3625-45.

52. Fones EM, Colman DR, Kraus EA, Nothaft DB, Poudel S, Rempfert KR, et al. Physiological adaptations to serpentinization in the Samail Ophiolite, Oman. ISME J. 2019;13:1750.

53. Meier DV, Pjevac P, Bach W, Hourdez S, Girguis PR, Vidoudez $\mathrm{C}$, et al. Niche partitioning of diverse sulfur-oxidizing bacteria at hydrothermal vents. ISME J. 2017;11:1545-58.

54. de Beer D, Sauter E, Niemann H, Kaul N, Foucher J-P, Witte U, et al. In situ fluxes and zonation of microbial activity in surface sediments of the Håkon Mosby Mud Volcano. Limnol Oceanogr. 2006;51:1315-31.

55. Rempfert KR, Miller HM, Bompard N, Nothaft D, Matter JM, Kelemen P, et al. Geological and geochemical controls on subsurface microbial life in the Samail ophiolite, Oman. Front Microbiol. 2017;8:56.

56. Woycheese KM, Meyer-Dombard DR, Cardace D, Argayosa AM, Arcilla CA. Out of the dark: transitional subsurface-to-surface microbial diversity in a terrestrial serpentinizing seep (Manleluag, Pangasinan, the Philippines). Front Microbiol. 2015;6:44.

57. Brazelton WJ, Thornton CN, Hyer A, Twing KI, Longino AA, Lang SQ, et al. Metagenomic identification of active methanogens and methanotrophs in serpentinite springs of the Voltri Massif, Italy. PeerJ. 2017;5:e2945.

58. Tavormina PL, Hatzenpichler R, McGlynn S, Chadwick G, Dawson KS, Connon SA, et al. Methyloprofundus sedimenti gen. nov., sp. nov., an obligate methanotroph from ocean sediment belonging to the 'deep sea-1' clade of marine methanotrophs. Int J Syst Evol Microbiol. 2015;65:251-9.

59. McCollom TM, Seewald JS. A reassessment of the potential for reduction of dissolved $\mathrm{CO}_{2}$ to hydrocarbons during serpentinization of olivine. Geochim Cosmochim Acta. 2001;65: 3769-78.

60. Seewald JS, Zolotov MY, McCollom T. Experimental investigation of single carbon compounds under hydrothermal conditions. Geochim Cosmochim Acta. 2006;70:446-60.

61. Smith AR, Kieft B, Mueller R, Fisk MR, Mason OU, Popa R, et al. Carbon fixation and energy metabolisms of a subseafloor olivine biofilm. ISME J. 2019;13:1737.

62. Adam PS, Borrel G, Gribaldo S. Evolutionary history of carbon monoxide dehydrogenase/acetyl-CoA synthase, one of the oldest enzymatic complexes. Proc Natl Acad Sci USA. 2018;115: E1166-73.

63. Morrill PL, Brazelton WJ, Kohl L, Rietze A, Miles SM, Kavanagh $\mathrm{H}$, et al. Investigations of potential microbial methanogenic and carbon monoxide utilization pathways in ultra-basic reducing springs associated with present-day continental serpentinization: the Tablelands, NL, CAN. Front Microbiol. 2014;5:613.

64. Lopez-Lazaro C, Bachaud P, Moretti I, Ferrando N. Predicting the phase behavior of hydrogen in $\mathrm{NaCl}$ brines by molecular simulation for geological applications. BSGF Earth Sci Bull. 2019; 190:7.

65. Buckel W, Thauer RK. Energy conservation via electron bifurcating ferredoxin reduction and proton $/ \mathrm{Na}(+)$ translocating ferredoxin oxidation. Biochim Biophys Acta. 2013; 1827:94-113.

66. Suzuki S, Nealson KH, Ishii S. Genomic and in-situ transcriptomic characterization of the candidate phylum NPL-UPL2 from highly alkaline highly reducing serpentinized groundwater. Front Microbiol. 2018;9:3141. 
67. Peters JW, Schut GJ, Boyd ES, Mulder DW, Shepard EM, Broderick $\mathrm{JB}$, et al. [FeFe]- and [NiFe]-hydrogenase diversity, mechanism, and maturation. Biochim Biophys Acta. 2015;1853:1350-69.

68. McGonigle JM, Lang SQ, Brazelton WJ. Genomic evidence for formate metabolism by Chloroflexi as the key to unlocking deep carbon in Lost City microbial ecosystems. Appl Environ Microbiol. 2020;86:e02583-19.

69. Burgdorf T, van der Linden E, Bernhard M, Yuan Yin Q, Back $\mathrm{JW}$, Hartog $\mathrm{AF}$, et al. The soluble $\mathrm{NAD}^{+}$-reducing $[\mathrm{NiFe}]-$ hydrogenase from Ralstonia eutropha $\mathrm{H} 16$ consists of six subunits and can be specifically activated by NADPH. J Bacteriol. 2005; 187:3122-32.

70. Alt JC, Schwarzenbach EM, Früh-Green GL, Shanks WC, Bernasconi SM, Garrido CJ, et al. The role of serpentinites in cycling of carbon and sulfur: Seafloor serpentinization and subduction metamorphism. Lithos. 2013;178:40-54.

71. Zhong H, Lehtovirta-Morley L, Liu J, Zheng Y, Lin H, Song D, et al. Novel insights into the Thaumarchaeota in the deepest oceans: their metabolism and potential adaptation mechanisms. Microbiome. 2020;8:78. 